\title{
Implant-related inflammation, diagnosis, and treatment
}

\author{
Ui Jin KO, Wook Tae KIM, Kyung Sook HWANG* \\ Dept. of Dent. Tech., Shin Han Univ., Korea
}

Introduction: Since the implant has no nerves and blood vessels histologically, the disease is very simple. Therefore, it can be divided into two diseases related to implant inflammation. Among them, peri-implant mucositis refers to inflammation limited to the peri-implant mucosa without signs of resorption of the alveolar bone supporting the implant. This can be cured by simply removing plaque as oral hygiene management. On the other hand, peri-implantitis is a destructive inflammation affecting the soft and hard tissue around the dental implant. In other words, since there is no periodontal ligament directly invading the implant around the implant, inflammatory cells directly penetrate into the bone marrow, resulting in faster bone destruction than in natural teeth. In the case of a compound implant, there is a gap and a hole between the actual implant fixture and the superstructure, so that bacteria can enter the oral cavity. Later, these germs return to the relevant tissues and cause peri-implantitis.

Causes: cement residue, incomplete abutment-fixture fit, improperly shaped prosthesis, failure to control plaque, excessive load, etc. Contributing factors include poor oral hygiene, history of periodontitis, smoking, diabetes, alcoholism, genetic predisposition. Lack of phosphorus, keratinized gingiva, etc.

Diagnosis: If a depth of more than $6 \mathrm{~mm}$ is found with a very weak probe, it is unconditionally judged to have peri-implantitis. In this case, bleeding during the probe is the most important diagnostic factor.

Treatment: As a non-surgical treatment, it is preferentially selected for peri-implant mucositis and early peri-implantitis. It has little effect in peri-implantitis with significant bone loss. Also, if bone resorption has progressed up to 3 or more threads or the probe depth is more than $5 \mathrm{~mm}$, it is not very effective. Methods include oral hygiene education, dead tissue removal, surface contaminant removal, ultrasonic device, laser device, mechanical sofa, antibiotic prescription, mouthwash and cleaning with chlorhexidine. As surgical treatment, regenerative treatment can be attempted for intraosseous defects. However, in the case of an extraosseous defect, excisional surgery should be considered first. It creates a favorable environment around implants for removal and maintenance of infectious agents. In severe cases, suppuration occurs, and pathological loss of alveolar bone on radiographs is $2 \mathrm{~mm}$ or more.

Keywords: peri-implant mucositis, peri-implantitis, histological anatomical implant

Acknowledgement: This study is supported by Uniance's Central Research Institute.

Copyright (C) 2021. Korean Academy of Preventive Dentistry. All rights reserved.

This is an Open Access article distributed under the terms of the Creative Commons Attribution Non-Commercial License (http://creativecommons.org/licenses/ by-nc/4.0) which permits unrestricted non-commercial use, distribution, and reproduction in any medium, provided the original work is properly cited. 